\title{
Investigation of Parameters on Small Signal Stability of 206.1 MVA Generators
}

\author{
Waluyo, Gregorius Grady Krisshandy and Nandang Taryana \\ Department of Electrical Engineering, Institut Teknologi Nasional Bandung, \\ 40124 Bandung, Indonesia, waluyo@itenas.ac.id
}

\begin{abstract}
This research was investigation on small signal stability on two generators. The analyses were based on the single machine infinite bus with the increasing load as $25 \%$ of $175 \mathrm{MW}$ and 85 MVAR. It was yielded the damping ratios, oscillating frequencies and stability conditions. Furthermore, it could be calculated the system synchronizing and damping constants. The results for the active and reactive powers and for the terminal and bus voltages in both generators were the same as the oscillating in 8-9.3 sec. The chosen data for the computations were at the time before the increasing load in $7.8 \mathrm{sec}$ with every sampling oscillation as $0.05 \mathrm{sec}$. The results were the system in asymptote stables with the 0.0043-0.0044 damping ratios, $1.2108-1.2132 \mathrm{~Hz}$ for oscillating frequencies, around 1.47 pu torque for synchronizing constant and $0.50 \mathrm{pu}$ torque per changing speed for the damping constant.
\end{abstract}

Key words: Asymptote stable, damping constant, damping ratio, synchronizing constant, small signal stability, oscillation

\section{INTRODUCTION}

Stability is a ability of system to remain stable in face of interference. The stability plays an important role in an electric grid system. Therefore, the generation should be remained in a stable condition, both in the face of small and large disturbances. The small disturbances in a generator can disturb the frequency, load and voltage on the system. They are caused by minor changes at the load and generation such as accretion rotor angle due to lack of synchronization and insufficient torque of rotor oscillation damping. The ability of system to be stabilized in the synchronous system due to minor disturbances is called small-signal stability (Kundur, 1994). Stability is the most important constraint in power system operation (Saini et al., 2013; Sabapathi, 2015; Sulistiawati et al., 2012; Gan et al., 2000). A damping of oscillations has been recognized as important in power system operations. Oscillations among generators appeared as soon as the generators operate in parallel and it tend to be continually excited (Grigsby, 2012). The synchronous generator may sometimes be able to withstand a large impact but it may fail to retain synchronism under a small impact due to growing oscillations (Bunnoon, 2013; Maity et al., 2013). The general concepts were associated with applying power system stabilizers utilizing shaft speed, $\mathrm{AC}$ bus frequency and electrical power inputs (Ranjan et al., 1993; Vu and Turitsyn, 2016; Amin and Aqilah, 2013; Patel et al., 2002; Salim and Ramos, 2012;
Larsen and Swann, 1981; Pavella et al., 2000). The eigenvalue will influence the limits on power system that contains oscillations due to variety of interactions among components. The small signal stability analysis is very useful due to interaction of distributed energy resources with the utility system. It was possible to improve the small-signal stability margin by including constraints on the eigenvalue real parts. The use of energy storage enhanced the small-signal stability (Lerm et al., 2001; Dong, 1998; Kumar et al., 2009; Ogata, 2002; Gulvender, 2016; Condren and Gedra, 2006; Canizares et al., 2017; Kanchanaharuthai, 2012). The system dynamic behavior can be described by following vector-matrix form (Kundur, 1994):

$$
\dot{\mathrm{x}}=\mathrm{f}(\mathrm{x}, \mathrm{u}, \mathrm{f})
$$

Where:

$$
\mathrm{x}=\left[\begin{array}{c}
\mathrm{x}_{1} \\
\ldots \\
\mathrm{x}_{\mathrm{n}}
\end{array}\right], \mathrm{u}=\left[\begin{array}{c}
\mathrm{u}_{1} \\
\ldots \\
\mathrm{u}_{\mathrm{n}}
\end{array}\right], \mathrm{f}=\left[\begin{array}{c}
\mathrm{f}_{1} \\
\ldots \\
\mathrm{f}_{\mathrm{n}}
\end{array}\right]
$$

The column vector $\mathrm{x}$ leads the state vector and its inputs $x_{1}$ is a state variable. While, the column vector $u$ declares the input system, $t$ is expressed in its own time and derivative of state variable $\mathrm{x}$ with respect to time.

There were many researches those related to stability and voltage collapse, especially, in the Self-Excited Induction Generators (SEIGs) and Doubly Fed Induction Generators (DFIGs) (Rajambal et al., 2009; Sun et al., 2013;

Corresponding Author: Waluyo, Department of Electrical Engineering, Institut Teknologi Nasional Bandung, 40124 Bandung, Indonesia, waluyo@itenas.ac.id 
Shawon et al., 2013; Adachi and Yokoyama, 2016; Shi et al., 2011; Vittal et al., 2009; Mishra et al., 2009; Pozhhana et al., 2016). Nevertheless, this research was focused on the synchronous generators, another type of induction generators.

The research related to small signal stability of generators is need to be further developed. Usually, the analysis on the stability involves only one or some behaviors of parameters and less consider to the real parameters on a generator. Therefore, it was necessary to investigate the more parameters on the small signal stability simultaneously and considering the real generator parameters. The parameters were not dawdled. The objectives of research were to obtain the small signals, based on the 206.1 MVA generator parameters in the form of relationship on the additional incoming load, the output signals of active and reactive powers, the terminal and system bus voltages of generators. Furthermore, it was determined the stability of system during small disturbances, parameters of small signal stability such as synchronous constant, damping constant, damping ratio and the oscillating frequency during small disturbance. Besides that, it was identified the problems of small signal stability values of oscillating frequency in the generation system. The analyzing signal changes of active power, reactive power, voltage terminals and bus voltages during small disturbances using the simulations. The analysis was performed in the machine infinite bus and the two typical generators.

\section{MATERIALS AND METHODS}

Figure 1 describes the research stages in the analysis of generator small-signal stability shortly. First step, it should be done was to collect the data of generation system.

Furthermore, the system was modeled in a block diagram, that the generator supplied power to the system infinite bus. The next step was simulating the model, where the single line is shown in Fig. 2a.

The data were analyzed by using the simulations, which could then be computed the parameters to form a state matrix. Furthermore, it was obtained the eigenvalues of system and it was known from the real values whether the system was stable or not. If the value was the real negative, the system asymptote was stable, otherwise the system was unstable. It could also, be obtained the value of damping ratio, oscillating frequency, synchronous constant and the damping constant. The model block diagram of small-signal stability can be seen in Fig. $2 \mathrm{~b}$. While, the modeling for the excitation system is shown in Fig. 3 (Anonymous, 2015).

In a small-signal stability analysis, it should be noted that the study was conducted when the condition of interruption was in the flow and flux linkage, so that, it

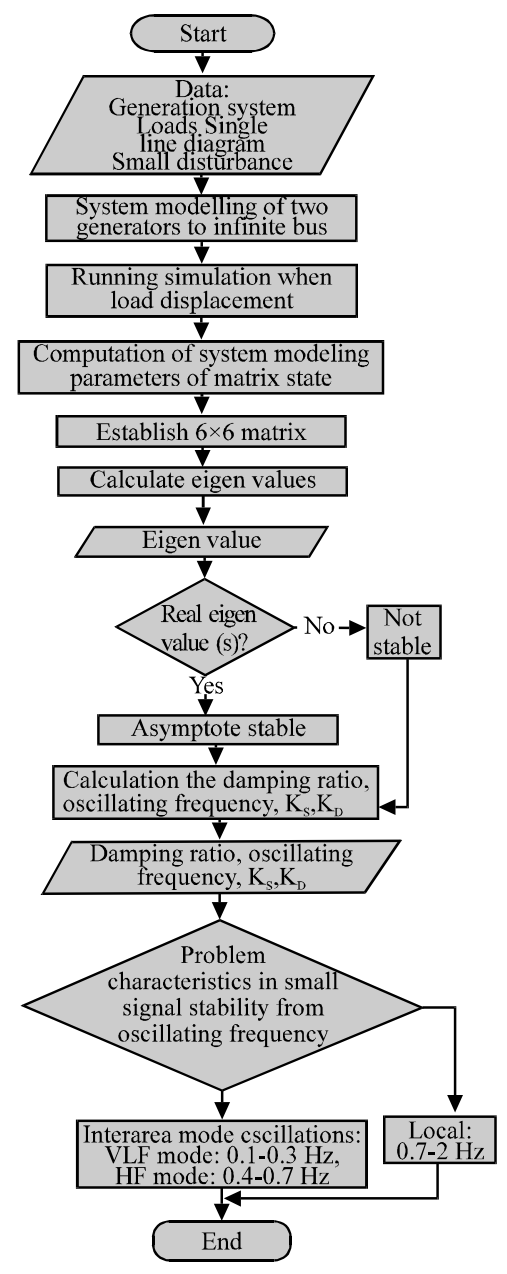

Fig. 1: Flow chart research stages

was need to add an incremental saturation factor. The matrix was mainly influenced by the field changes, revealed as:

$$
\begin{aligned}
{\left[\begin{array}{l}
\Delta \omega_{\mathrm{r}} \\
\Delta \delta \\
\Delta \psi_{\mathrm{fd}} \\
\Delta v_{1} \\
\Delta v_{2} \\
\Delta v_{3}
\end{array}\right]=} & {\left[\begin{array}{cccccc}
\mathrm{a}_{11} & \mathrm{a}_{12} & \mathrm{a}_{13} & 0 & 0 & 0 \\
\mathrm{a}_{21} & 0 & 0 & 0 & 0 & 0 \\
0 & \mathrm{a}_{32 \text { (incr) }} & \mathrm{a}_{33(\text { (nncr) }} & \mathrm{a}_{34} & 0 & \mathrm{a}_{36} \\
0 & \mathrm{a}_{42} & \mathrm{a}_{43} & \mathrm{a}_{44} & 0 & 0 \\
\mathrm{a}_{51} & \mathrm{a}_{52} & \mathrm{a}_{53} & 0 & \mathrm{a}_{55} & 0 \\
\mathrm{a}_{61} & \mathrm{a}_{62} & \mathrm{a}_{63} & 0 & \mathrm{a}_{65} & \mathrm{a}_{66}
\end{array}\right] } \\
& {\left[\begin{array}{c}
\Delta \omega_{\mathrm{r}} \\
\Delta \delta \\
\Delta \delta \\
\Delta \psi_{\mathrm{ft}} \\
\Delta v_{1} \\
\Delta v_{2} \\
\Delta v_{3}
\end{array}\right]+\left[\begin{array}{c}
\mathrm{b}_{11} \\
0 \\
0 \\
0 \\
\mathrm{~b}_{51} \\
\mathrm{~b}_{61}
\end{array}\right] \Delta \mathrm{T}_{\mathrm{m}} }
\end{aligned}
$$




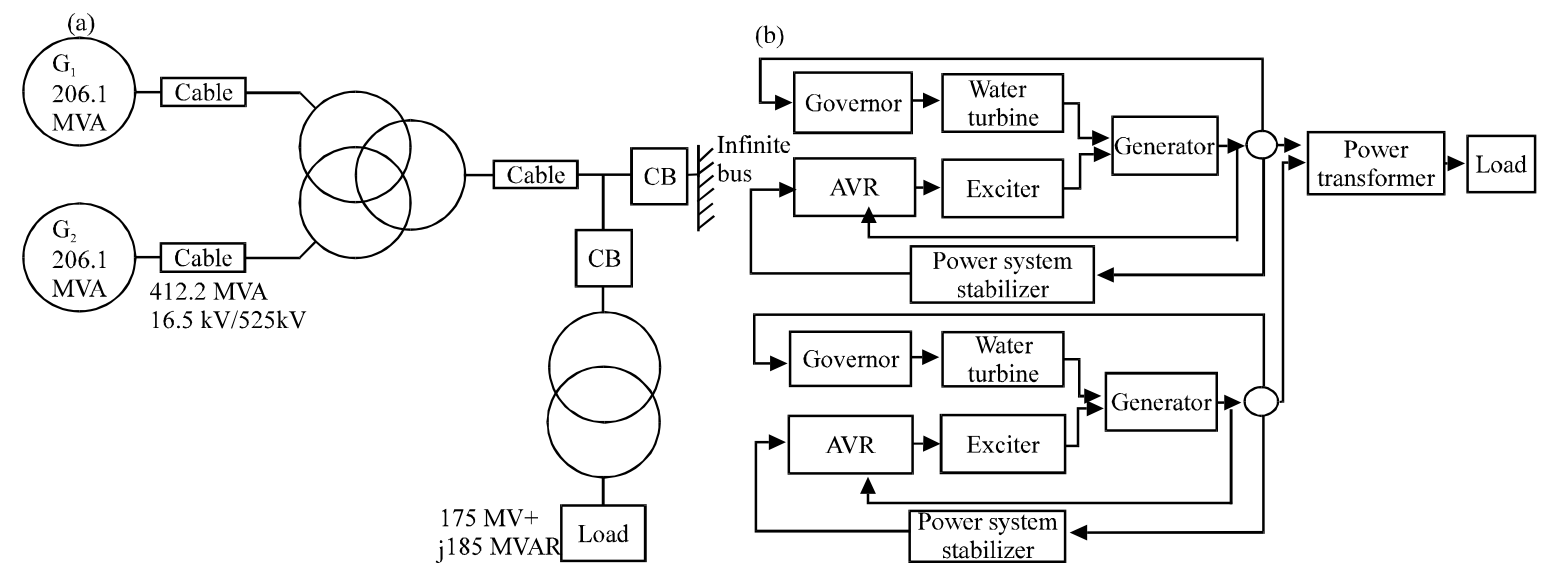

Fig. 2: a) System model of two generators and b) Small signal stability block diagram

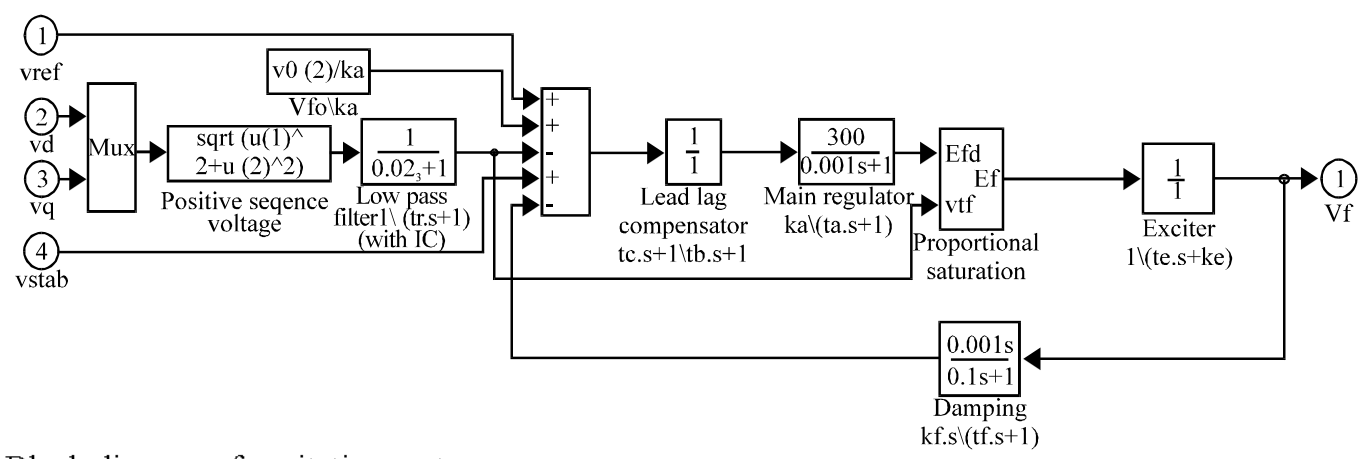

Fig. 3: Block diagram of excitation system

From the eigenvalues of state-matrix, it would be calculated the values of damping ratio and oscillating frequency, so that, the problems could be identified whether as local or global problems. The local problems could be distinguished by two causes, namely when the generator suffered from a rotor angle oscillation, commonly called a local plant mode oscillation and at a fraction generator adjacent experiencing oscillation or called as intermachine or interplant mode oscillation. Both oscillations might be identified by the oscillation frequencies between 0.7 and $2 \mathrm{~Hz}$. Otherwise, the global problem was caused by an interaction among generators largely as an interarea mode oscillation. Based on the oscillation frequencies, it could be divided into two categories as very low and higher frequencies. The former involved all generators in the system with the frequency range between 0.1 and $0.3 \mathrm{~Hz}$ and the latter ranged between 0.4 and $0.7 \mathrm{~Hz}$.

\section{RESULTS AND DISCUSSION}

In this study, it was used two identical generators where the parameters can be listed in Table 1.

\begin{tabular}{ll} 
Table 1: Generator parameters & \\
\hline Parameters & Values \\
\hline $\mathrm{S}(\mathrm{MVA})$ & 206.1 \\
$\mathrm{~V}(\mathrm{kV})$ & 16.5 \\
$\mathrm{I}(\mathrm{kA})$ & 7.212 \\
$\mathrm{f}(\mathrm{Hz})$ & 50 \\
$\mathrm{pf}$ & 0.85 lagging \\
$\mathrm{n}$ & $333(\mathrm{ppm})$ \\
Reactance (pu) $\mathbf{1} \mathbf{p u}=\mathbf{1 . 3 2} \Omega$ & \\
$\mathrm{X}_{\mathrm{ds}}$ & 0.93 \\
$\mathrm{X}_{\mathrm{du}}$ & 1.09 \\
$\mathrm{D}_{\mathrm{d}}{ }^{\prime}$ & 0.199 \\
$\mathrm{X}_{\mathrm{d}}{ }^{\prime \prime}$ & 0.128 \\
$\mathrm{X}_{\mathrm{q}}$ & 0.65 \\
$\mathrm{X}_{\mathrm{d}}{ }^{\prime}$ & 0.151 \\
$\mathrm{X}_{2}$ & 0.142 \\
$\mathrm{X}_{1}$ & 0.134 \\
$\mathrm{X}_{\mathrm{o}}$ & 0.105 \\
Time constant (sec) & \\
$\mathrm{T}_{\mathrm{do}}{ }^{\prime}$ & 12.8 \\
$\mathrm{~T}_{\mathrm{d}}{ }^{\prime}$ & 2.22 \\
$\mathrm{~T}_{\mathrm{d}}{ }^{\prime \prime}$ & 0.063 \\
$\mathrm{~T}_{\mathrm{d}}$ & 0.20 \\
\hline
\end{tabular}

The small-signal stability calculations were required AVR, exciter and PSS. These parameters were also, identical for two generators as shown in Table 2 .

Figure 4 shows that the generator experienced an oscillation when starting in the beginning of the system 


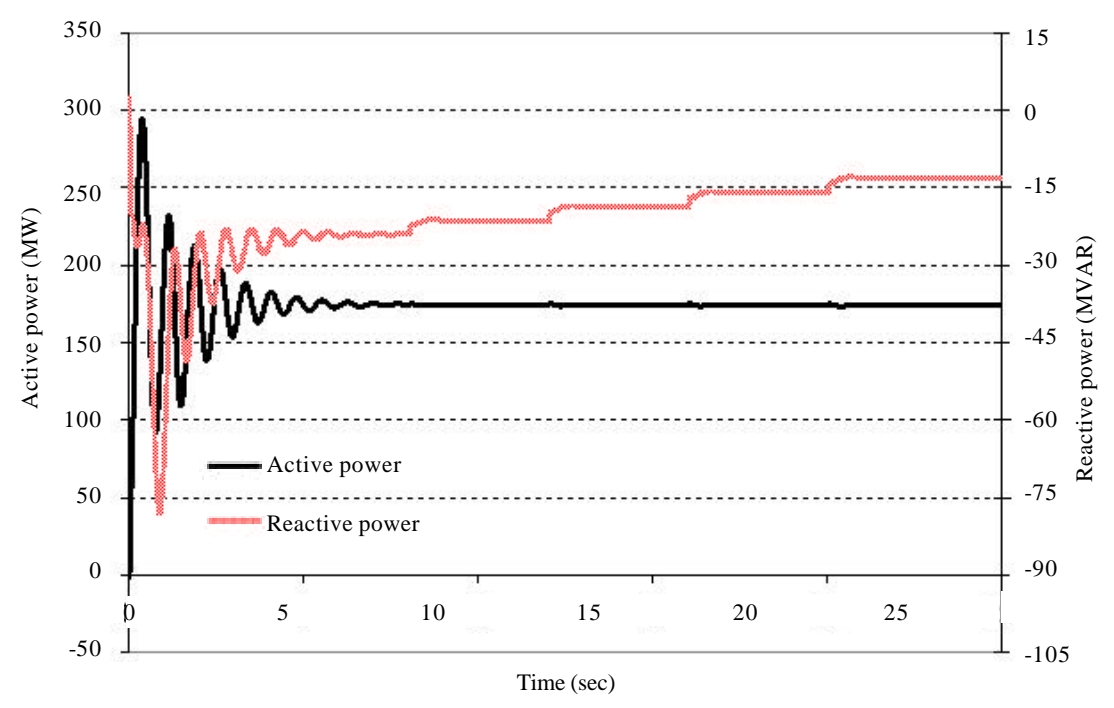

Fig. 4: Active and reactive power charts of generator 1

Table 2: Excitation system and PSS parameters

\begin{tabular}{ll}
\hline Parameters & Values \\
\hline Excitation system & \\
$\mathrm{T}_{\mathrm{r}}(\mathrm{sec})$ & $20 \times 10^{-3}$ \\
$\mathrm{~K}_{\mathrm{a}}$ & 300 \\
$\mathrm{~T}_{\mathrm{a}}(\mathrm{sec})$ & 0.001 \\
$\mathrm{~K}_{\mathrm{e}}$ & 1 \\
$\mathrm{~T}_{\mathrm{e}}$ & 0 \\
$\mathrm{~T}_{\mathrm{b}}(\mathrm{sec})$ & 0 \\
$\mathrm{~T}_{\mathrm{c}}(\mathrm{sec})$ & 0 \\
$\mathrm{~K}_{\mathrm{f}}$ & 0.001 \\
$\mathrm{~T}_{\mathrm{f}}(\mathrm{sec})$ & 0.1 \\
$\mathrm{E}_{\text {fmin }}(\mathrm{pu})$ & -11.5 \\
$\mathrm{E}_{\text {fmax }}(\mathrm{pu})$ & 11.5 \\
$\mathrm{~K}_{\mathrm{p}}$ & 0 \\
$\mathrm{~V}_{\text {to }}(\mathrm{pu})$ & 1 \\
$\mathrm{~V}_{\text {fo }}(\mathrm{pu})$ & 1.00712 \\
PSS & \\
Sensor time constant & $30 \times 10^{-3}$ \\
Gain & 0.5 \\
Wash-out time constant & 2 \\
$\mathrm{~T}_{1}$ & $50 \times 10^{-3}$ \\
$\mathrm{~T}_{2}$ & 0.2 \\
$\mathrm{~V}_{\text {smin }}$ & -0.2 \\
$\mathrm{~V}_{\text {smax }}$ & 0.2 \\
\hline
\end{tabular}

in the second $0-7$ and that time, there was an additional load on the second of $8,12,16$ and 20 . The active and reactive power oscillations at the baseline or starting were occurred due to plant or system seeking an equilibrium point when connected to the infinite bus. Nevertheless, this oscillation was still within the safe ability limits of system itself. The highest magnitude was occurred on the second of 0.35 as $294.6 \mathrm{MW}$ and at the second of 0.55 , decreased as 199.4 MW. This meant that the highest oscillation was occurred for $0.2 \mathrm{sec}$. For every new equilibrium condition, the system would experience a dense oscillation for $0.08 \mathrm{sec}$ for early adaptation.
Otherwise, the reactive power also, experienced an oscillation, however, it had a different behaviour. It tent to increase, especially, on the additional loads at $8,12,16$ and $20 \mathrm{sec}$.

The figure described the active power oscillations of the generator 1 , due to the additional load of $175 \mathrm{MW}$ and 85 MVAR with the oscillations that more dense from $8-8.06 \mathrm{sec}$ where the rest of oscillations tent to swing down to the steady state in $9.3 \mathrm{sec}$. This occurrence was caused the system search for a new equilibrium point. The system to warded to the steady state after $1.3 \mathrm{sec}$ oscillation. The active power oscillation itself reached the maximum point of $154.57 \mathrm{MW}$ when in $8.05 \mathrm{sec}$. In this simulation, the generator 1 and 2 were typical, so, the active power which issued for both generators were the same, when starting and oscillation.

In a contrast to active power that occurred during the dense oscillation of $0.06 \mathrm{sec}$, the reactive power oscillation signal that was densely occurred during 0.08 sec whether when searching for a new equilibrium state with the largest magnitude of -25.63 MVAR when oscillation in second of 8.05 or -19.168 MVAR when starting. The reactive power of generator 1 was in a leading state because the generator was shortage of reactive power, so that, it utilized amount of reactive power on the infinite bus. Besides that, this case was to keep the voltage in amount corresponding to the infinite bus itself. As load addition, the reactive power also experienced an oscillation as illustrated in the chart.

Figure 5 shows the oscillating crest and trough magnitudes of active and reactive power due to additional loads on seconds of $8,12,16$ and 20 . The oscillating 


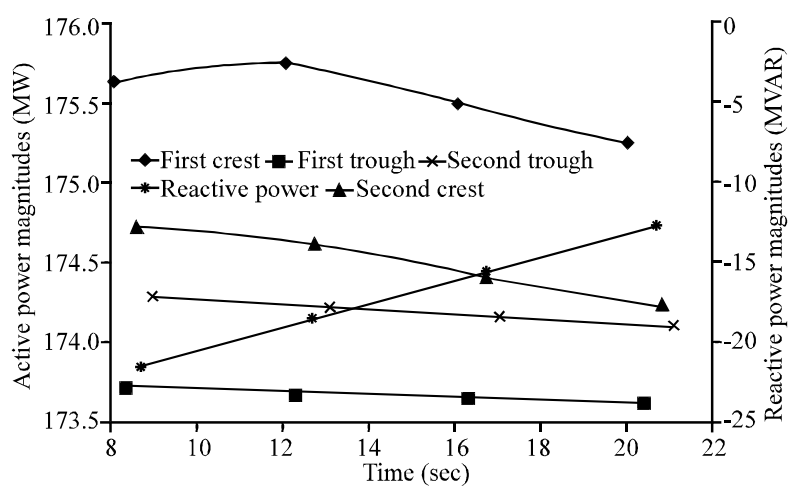

Fig. 5: Oscillating magnitudes of active and reactive powers

magnitudes tentded to decrease as the second of additional loads increased. This case was occurred significantly enough, especially, for the first crest and first trough. This case was also, occurred on the second crest and the second trough of oscillating waves but not so, significant. These occurrences were also, applied for the reactive power ones, however, they were in negative values. Therefore, it was more resistant to the additional loads on the system due to the power in the system would be greater than the previous ones.

Figure 6a describes the speed graph of the generator 1 for $25 \mathrm{sec}$ in which there were the additional loads at the second to $8,12,16$ and 20 with each rise level as $25 \%$ of $175 \mathrm{MW}$ and $85 \mathrm{MVAR}$. From the figures, it can be seen the starting oscillation occurs because the generator seek a balance in the face of infinite bus. The oscillation itself was occurred the starting for $7 \mathrm{sec}$ from second $0-7$, in which the maximum amplitude was equal to around $336.88 \mathrm{rpm}$. Nevertheless, it was still within safe limits generator. For this condition, there were small oscillations due to additional load on the network $500 \mathrm{kV}$. One of effects of the minor disturbance was an oscillation in the generator rotor angle which can be shown in Fig. 6b. It shows the oscillations in the generator, either when starting or due to the additional load. When starting, its own oscillation occurs were the minimum of -37.28 and $-27.51^{\circ}$ of first and second values, respectively where the oscillation occurs during $7 \mathrm{sec}$. This case was due to the current system was beginning to adjust to the balance of infinite bus system. The rotor small angle oscillation was also, experienced due to the load additions.

Figure $6 \mathrm{c}$ describes the magnitude of the voltage on the terminal and bus for the generator 1. When starting, the system voltages were experiencing the oscillations for $7 \mathrm{sec}$. The oscillations would closer occur during the second of $0-0.08$ because like as the previous section that the system adapted to the load condition or in this case, the infinite bus. The greatest amplitudes were occurred in seconds to 0 as $17.1 \mathrm{kV}$ and $540.7 \mathrm{kV}$ for the terminal and bus voltage, respectively. When there were the additional loads at the seconds to $8,12,16$ and 20 , the voltage oscillations were also occurred, although, smaller compared to the starting conditions. The terminal voltage tent to be constant, closed to $16.5 \mathrm{kV}$. Nevertheless, the bus voltage tended to decrease due to the additional loads to the nominal voltage of $500 \mathrm{kV}$. The voltage on the system should be kept as the constant value, so that, the expected changes were not significantly influenced by the changes of power.

Figure 7 shows the synchronizing constant, damping constant and oscillating frequency charts of generator 2 due to additional load at second of 8 . It is shown that the synchronizing and damping constants were relatively constant. The rotor oscillating frequency would vary slightly due to additional loads.

The oscillation due to the load addition was not too large because the voltage must be kept to its reference of infinite bus. The highest signal voltage amplitude at the second of 8.55 as $0.9997 \mathrm{pu}$ or $16.494 \mathrm{kV}$. While the time required returning to the steady state was $1.3 \mathrm{sec}$.

Actually, the phase angle due to the load addition did not change significantly because basically, the power factor for this system on the network was constantly kept, so that, the angle did not change too. The smallest voltage, phase angle was at $8.3 \mathrm{sec}$ as $9.057^{\circ}$ and the highest one as $9.16^{\circ}$. Thus, the difference between the largest and smallest angles was $0.103^{\circ}$. The terminal voltages for both generators and both starting and oscillating conditions were same, due to both generators were identical.

The $\mathrm{E}_{\mathrm{B}}$ bus voltage oscillating chart was occurred when the starting because the system searched for the appropriate voltage to the condition on the infinite bus. The oscillation was also, occurred when there was an additional load, however, it was not too significant. This phenomenon could be attributed to the system that would keep $E_{\mathrm{B}}$ voltage remained constant, since, the voltage was the reference to be kept. The oscillation was occurred when starting for $3 \mathrm{sec}$ from $0-3 \mathrm{sec}$ with the dense oscillation was occurred during $0.08 \mathrm{sec}$ with the maximum amplitude of $1.03 \mathrm{pu}$ or $540.8 \mathrm{kV}$. When there was an additional load, it would yield the oscillation from $8-9.3 \mathrm{sec}$ or during $1.3 \mathrm{sec}$.

Nevertheless, that interesting one, it was occurred small voltage drop of $0.001 \mathrm{pu}$ or $500 \mathrm{~V}$, due to the load addition. The phase angle bus voltage of $500 \mathrm{kV}$ did not change significantly due to the load addition because the power factor was kept to be constant. This was evidenced 

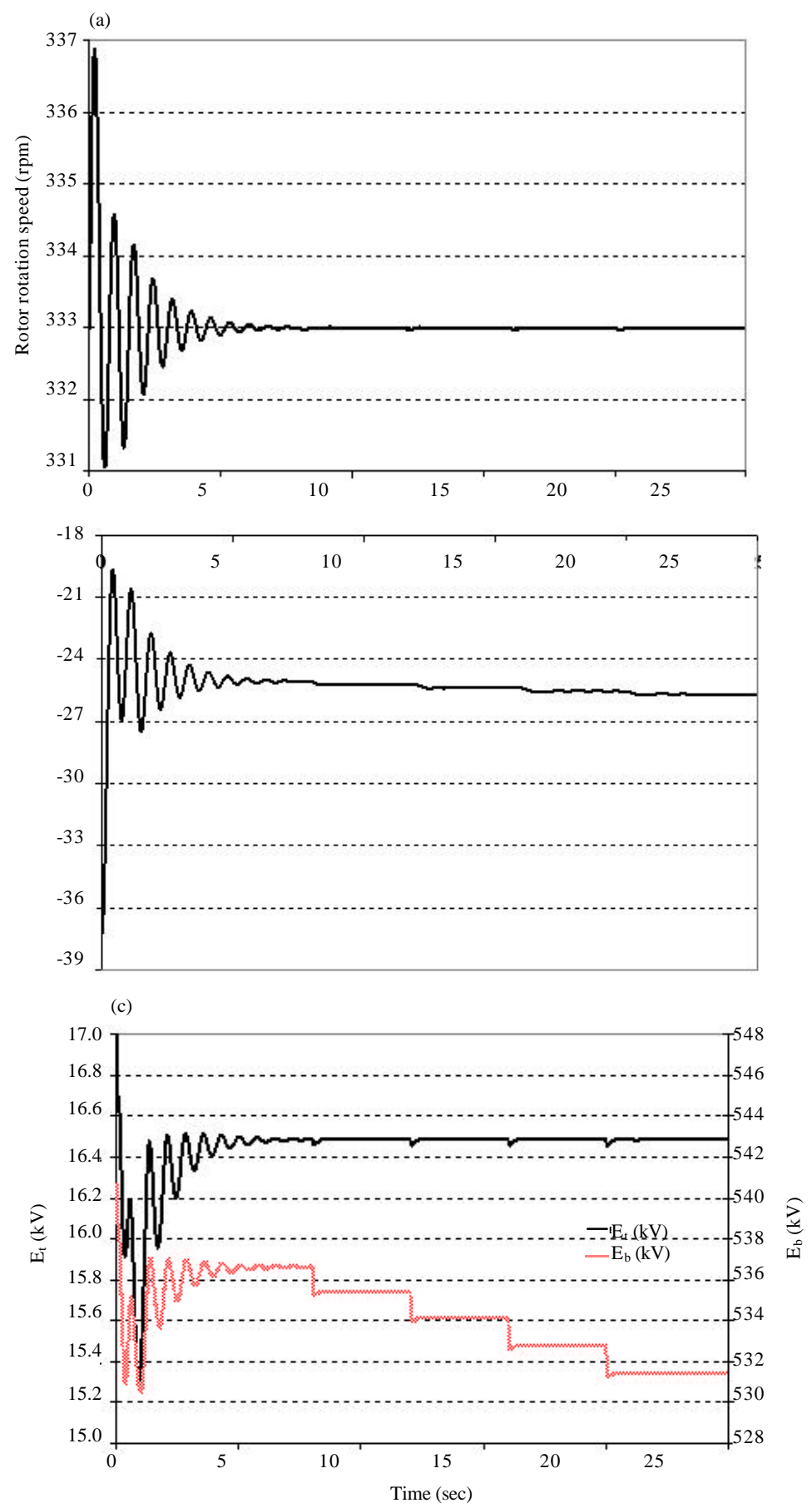

Fig. 6: a) Rotor rotation speed; b) Rotor angle and c) Terminal and bus voltage charts

by the smallest angle of $30.29^{\circ}$ at $8.25 \mathrm{sec}$ and the largest angle of $30.38^{\circ}$ at $8.00 \mathrm{sec}$. Thus, the difference between the largest and smallest angles was $0.09^{\circ}$.

The speed chart of the generator 1 was one of the parameters that the system was whether stable or not. It could be seen from the rotation generator when in the face of large system or fault. In this case, it was the addition of load on the network system of $500 \mathrm{kV}, 175 \mathrm{MW}$ and 85 MVAR. The oscillation for the starting occurrence within $3.5 \mathrm{sec}$ from zero to $3.5 \mathrm{sec}$ in which the maximum speed was equal to 1.008 pu or $335.7 \mathrm{rpm}$. Where, it was still within safe limits. 


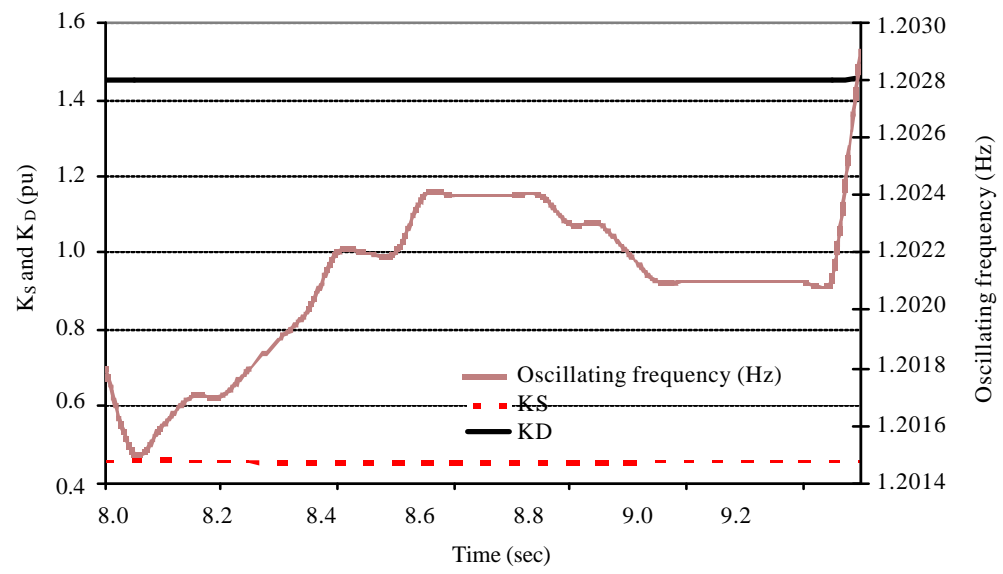

Fig. 7: Synchronizing constant, damping constant and oscillating frequency charts of generator 2 due to additional load at second of 8

Table 3: Synchronizing and damping constants and oscillating frequency

\begin{tabular}{lccc}
\hline $\mathrm{t}(\mathrm{sec})$ & $\mathrm{K}_{\mathrm{S}}(\mathrm{pu})$ & $\mathrm{K}_{\mathrm{D}}(\mathrm{pu})$ & Oscillation frequency $(\mathrm{Hz})$ \\
\hline 8.00 & 1.4771 & 0.5368 & 1.2121 \\
8.05 & 1.4732 & 0.5395 & 1.2015 \\
8.10 & 1.4735 & 0.5365 & 1.2017 \\
8.15 & 1.4737 & 0.5336 & 1.2108 \\
8.20 & 1.4738 & 0.5316 & 1.2108 \\
12.00 & 1.4779 & 0.5277 & 1.2125 \\
12.05 & 1.4779 & 0.5321 & 1.2125 \\
12.10 & 1.4751 & 0.5293 & 1.2113 \\
12.15 & 1.4758 & 0.5261 & 1.2113 \\
12.20 & 1.4757 & 0.5239 & 1.2116 \\
16.00 & 1.4797 & 0.5190 & 1.2132 \\
16.05 & 1.4761 & 0.5229 & 1.2117 \\
16.10 & 1.4766 & 0.5205 & 1.2119 \\
16.15 & 1.4772 & 0.5175 & 1.2122 \\
16.20 & 1.4780 & 0.5149 & 1.2125 \\
20.00 & 1.4814 & 0.5103 & 1.2139 \\
20.05 & 1.4778 & 0.5137 & 1.2124 \\
20.10 & 1.4783 & 0.5115 & 1.2126 \\
20.15 & 1.4788 & 0.5090 & 1.2128 \\
20.20 & 1.4796 & 0.5067 & 1.2132 \\
\hline
\end{tabular}

Because the load addition, the generator should supply more power than the previous one and lead generators must achieve the appropriate rotation speed, so that, the power could be well supplied and the speed of generator back to its steady state at the second to 9.3 . The generators of 1 and 2 , in this simulation were identical, so that, the speed of generator rotor was the same when both starting and oscillation.

In the calculations of small signal, it would be divided into several periods based on the oscillation chart. As a reference of small signal stability, the calculations on the initial conditions were done immediately before the load addition, in this case, in the second to 7.8. Then, it was resumed, when the power calculation was having the oscillation during the additional load of $175 \mathrm{MW}$ and 85 MVAR on the $500 \mathrm{kV}$ network. The testing with this load was based on the notion that small-signal stability was the ability of plant to maintain stability against small disturbances where the minor annoyances were disorders that could be linearized. The amount of additional load of $175 \mathrm{MW}$ based on the ability of generator nameplate as 206.1 MVA with 0.85 pf lagging, so that, it was obtained $175 \mathrm{MW}$ of power. Based on these data, the ability of current generator should be able to supply the infinite load bus and then there was the additional load. By effects of the load oscillations, there were evident from the charts of the figures, it could be expressed as minor nuisances because the minor disturbances could be changes of load, on the load or generating side in random, slow or fall-rise with its influence on the power flow was not significant.

As the samples on the results of eigenvalues, the second and third eigenvalues were complex numbers with a value of $-0.0286+7.5481 \mathrm{i}$ and $-0.0285-7.5481 \mathrm{i}$ where the real numbers stating the magnitude of damping in the system while the imaginary values were associated with the magnitude of damped oscillation frequency in the system when an increase in amplitude of oscillation. It could be determined the magnitude of damping ratio $\zeta$ as 0.0038 . The damping ratio determined the amount of deficiency or amplitude anomaly when an oscillation occur. It was also, obtained magnitude of the oscillation frequency to identify the problems in the mode of second to 7.8 as $1.2013 \mathrm{~Hz}$. From these results, it could be stated that the problem were inter-machine or inter-plant mode oscillations.

To determine the synchronization and damping constants of the system those were influenced by the excitation system and PSS, it was required calculation analysis of each component with $\mathrm{s}=-0.0285+7.5481 \mathrm{i}$. The synchronization constant was influenced by the 
magnitude of phase angle difference and the attenuation constant helped system to remain at actual speed. It meant the two components helped the system to stay in synchronous state during the change of phase angle and helped damping the speed of oscillation system.

Table 3 lists the part of generator oscillating data for calculation of small-signal stability those are indicated by the synchronizing constant, damping constant and the oscillating frequency. The obtained oscillation data were sampled every $0.05 \mathrm{sec}$. Based on the samples, the first times, seconds to $8,12,16$ and 20 , the values of $\mathrm{K}_{\mathrm{S}}$ and oscillation frequency would rise as the time increased. Otherwise, it was vice versa for $K_{D}$. Nevertheless, the system was still in stable condition.

By the magnitude of current oscillation frequency, the problem could be identified as intermachine or interplant mode oscillations. By the addition of load in increments of $25 \%$ of $175 \mathrm{MW}$ and $85 \mathrm{MVA}$ at the seconds to $8,12,16$ and 20 , they were resulting in the differences of $K_{S}, K_{D}$ and the oscillating frequency. This was caused by every system change was always looking for a new balance point. The oscillation frequency would increase as the synchronizing and damping torque coefficients increased, although, not exhibited significantly. It could be associated with the shape of the signal oscillations were almost the same but the magnitudes were different. Thus, each phase load increased, $\mathrm{K}_{\mathrm{S}}$ and $\mathrm{K}_{\mathrm{D}}$ also, went up to be able to keep the machine in synchronous condition and able to damp the oscillation speed. It meant the two components, AVR and PSS, helped the system to stay in synchronous condition during a change of phase angle and helped to damp the oscillation due to a speed change.

\section{CONCLUSION}

The disturbance in the simulated small signal applications with load testing out its entry on the second to 8 for $175 \mathrm{MW}+\mathrm{j} 85 \mathrm{MVAR}$, resulting oscillations in active power, reactive power, voltage terminal, rotor speed and rotor angle on each generator, so, even with infinite voltage on the bus for $1.3 \mathrm{sec}$. The charts were generated from both machines as the same due to identical characteristics. From the tests, it was known that the asymptote in the state of stable because based on the calculating results that the system had negative real eigenvalue for each condition. The faced problems were intermachine oscillations or the circumstances in which the two generators oscillated in one area with the oscillation frequency range between 1.2108-1.2132 Hz. When compared to previous additional load, the system had the oscillation frequency of $1.2 \mathrm{~Hz}$ which meant that it was smaller than that when the load addition. This case could be overcome by the AVR and PSS, in this test provided the synchronization and the damping constants as 1.47 and $0.50 \mathrm{pu}$ of speed change, respectively. The damping ratios of the system based on the calculations were obtained as $0.0043-0.0044$.

\section{ACKNOWLEDGEMENT}

The researchers would like to express the deepest appreciation to Indonesia Power of hydro electric power plant, which has supported to provide the data and Institut Teknologi Nasional Bandung (Itenas) for the financial support.

\section{REFERENCES}

Adachi, T. and A. Yokoyama, 2016. Improvement of small-signal stability of power system by controlling doubly fed induction generators of a large-capacity wind farm. J. Intl. Counc. Electr. Eng., 6: 117-125.

Amin, M. and N. Aqilah, 2013. Power system transient stability analysis using matlab software. $\mathrm{Ph}$.D Thesis, Universiti Tun Hussein Onn Malaysia, Parit Raja, Malaysia.

Anonymous, 2015. Simulink, user's guide, Matlab and Simulink. The MathWorks, Inc, Natick, Massachusetts, USA.

Bunnoon, P., 2013. Fault detection approaches to power system: State-of-the-art article reviews for searching a new approach in the future. Intl. J. Electr. Comput. Eng., 3: 553-560.

Canizares, C., T. Fernandes, E. Geraldi, L. Gerin-Lajoie and M. Gibbard et al., 2017. Benchmark models for the analysis and control of small-signal oscillatory dynamics in power systems. IEEE. Trans. Power Sys., 32: 715-722.

Condren, J. and T.W. Gedra, 2006. Expected-security-cost optimal power flow with small-signal stability constraints. IEEE. Trans. Power Sys., 21: 1736-1743.

Dong, Z.Y., 1998. Advanced methods for small signal stability analysis and control in modern power systems. Ph.D Thesis, University of Sydney New South Wales, Australia.

Gan, D., R.J. Thomas and R.D. Zimmerman, 2000. Stability-constrained optimal power flow. IEEE. Trans. Power Sys., 15: 535-540.

Grigsby, L.L., 2012. Electric Power Engineering Handbook. 2nd Edn./Vol. 5, CRC Press, Boca Raton, Florida, USA., ISBN:9780849392931,.

Gulvender, P.D., 2016. Study on mathematical modeling of power system stability analysis. Intl. J. Adv. Res. Electr., Electron. Instrum. Eng., 5: 5670-5676. 
Kanchanaharuthai, A., 2012. Small-signal stability, transient stability and voltage regulation enhancement of power systems with distributed renewable energy resources. Ph.D Thesis, Case Western Reserve University, Cleveland, Ohio.

Kumar, G.N., M.S. Kalavathi and B.R. Reddy, 2009. Eigen value techniques for small signal stability analysis in power system stability. J. Theor. Appl. Inf. Technol., 6: 181-194.

Kundur, P., 1994. Power System Stability and Control. McGraw-Hill Professional, New York, USA., ISBN-13: 978-0070359581, Pages: 1176.

Larsen, E.V. and D.A. Swann, 1981. Applying power system stabilizers Part I: General concepts. IEEE Trans. Power Apparatus Syst., PAS-100: 3017-3024.

Lerm, A.A., C.A. Canizares and N. Mithulananthan, 2001. Effects of limits in small signal stability analysis of power systems. Proceedings of the International Conference on Power Engineering Society Summer Meeting (Cat. No.01CH37262), July 15-19, 2001, IEEE, Vancouver, BC, Canada, ISBN:0-7803-7173-9, pp: 1805-1810.

Maity, A., K. Bhattacharya and A.N. Sanyal, 2013. Small signal stability analysis of synchronous generators connected to infinite bus. Intl. J. Emerging Technol. Adv. Eng., 3: 129-136.

Mishra, Y., S. Mishra, F. Li, Z.Y. Dong and R.C. Bansal, 2009. Small-signal stability analysis of a DFIG-based wind power system under different modes of operation. IEEE. Trans. Energy Convers., 24: 972-982.

Ogata, K., 2002. Modern Control Engineering. 4th Edn., Prentice Hall, New Jersey, USA., ISBN:9780130609076, Pages: 964.

Patel, R., T.S. Bhatti and D.P. Kothari, 2002. MATLAB/Simulink-based transient stability analysis of a multimachine power system. Intl. J. Electr. Eng. Educ., 39: 320-336.

Pavella, M., D. Ernst and D. Ruizvega, 2000. Transient Stability of Power Systems, a Unified Approach to Assessment and Control. Kluwer Academic Publishers, Boston, Massachusetts ISBN:9780792379638, Pages: 243.

Pozhhana, M., E.R. Rokb and J. Soltanic, 2016. Evaluation of DFIG placement on small signal stability in multi-machine power systems. Intl. Acad. J. Sci. Eng., 3: $119-132$.
Rajambal, K., P. Sanjeevikumar and Anbarasan, 2009. Identification of voltage collapse point in self excited induction generator. Songklanakarin J. Sci. Technol., 31: $441-446$.

Ranjan, R. K., M.A. Pai and P.W. Sauer, 1993. Analyticalformulation of small signal stability analysis of power systems with nonlinear load models. Sadhana, 18: 869-889.

Sabapathi, R.T.D., 2015. Transient stability analysis of grid using ETAP. Trans. Eng. Sci., 3: 45-48.

Saini, M.K., N.K. Yadav and N. Mehra, 2013. Transient stability analysis of multi machine power system with fact devices using MATLAB/Simulink environment. Intl. J. Comput. Eng. Manage., 16: 46-50.

Salim, R.H. and R.A. Ramos, 2012. A model-based approach for small-signal stability assessment of unbalanced power systems. IEEE. Trans. Power Sys., 27: 2006-2014.

Shawon, M.H., A. Al-Durra, C. Caruana and S.M. Muyeen, 2013. Small signal stability analysis of doubly fed induction generator including SDBR. J. Intl. Conf. Electr. Mach. Syst., 2: 31-39.

Shi, L., Z. Xu, C. Wang, L. Yao and Y. Ni, 2011. Impact of Intermittent Wind Generation on Power System Small Signal Stability. In: From Turbine to Wind Farms-Technical Requirements and Spin-Off Products, Krause, G. (Ed.). Intech Open, London, England, ISBN:978-953-307-237-1, pp: 161-182.

Sulistiawati, I.B., M. Abdillah and A. Soeprijanto, 2012. Prediction of critical clearing time of Java-Bali $500 \mathrm{kv}$ power system under multiple bus load changes using neural network based transient stability model. Intl. J. Electr. Eng. Inf., 4: 52-66.

Sun, B., Z. He, Y. Jia and K. Liao, 2013. Small-signal stability analysis of wind power system based on DFIG. Energy Power Eng., 5: 418-422.

Vittal, E., M. O'Malley and A. Keane, 2009. A small-signal stability analysis of DFIG wind generation. Proceedings of the 8th International Workshop on Large-Scale Integration of Wind Power into Power Systems as well as on Transmission Networks for Offshore Wind Farms, October 14-15, 2009 , Energynautics, Bremen, Germany, ISBN:978-3-9813870-1-8, pp: 1-9.

$\mathrm{Vu}, \mathrm{T} . \mathrm{L}$. and K. Turitsyn, 2016. Lyapunov functions family approach to transient stability assessment. IEEE. Trans. Power Sys., 31: 1269-1277. 